\title{
BUROCRACIA E SISTEMAS DE INFORMAÇÃO: DESAFIOS E PERSPECTIVAS PARA ORGANI- ZAÇÕES PÚBLICAS E PRIVADAS
}

\section{BUREAUCRACY AND INFORMATION SYSTEMS: CHALLENGES AND PERSPECTIVES TO PUBLIC AND PRIVATE ORGANIZATIONS}

Catarina Rosa e Silva de Albuquerque ${ }^{1}$ Alexsandro Bezerra Correia Bilar ${ }^{2}$ Flávia Fernanda da Silva Moura ${ }^{3}$

\section{RESUMO}

Os sistemas de informação têm desempenhado um papel importante no aperfeiçoamento dos processos organizacionais, seja em empresas privadas ou em instituições públicas. Entretanto, o binômio burocracia/ tecnologia ainda é um desafio para muitas organizações. Este artigo, pautado por uma pesquisa qualitativa e de finalidade exploratória, buscou averiguar, através de uma revisão de literatura, as principais características, disfunções e relações existentes entre o modelo burocrático weberiano e os sistemas de informação no atual contexto organizacional. Constatou-se que o avanço da tecnologia da informação nos setores público e privado possibilitou não apenas a sofisticação de seus mecanismos de controle, mas também aprimorou seus processos de tomada de decisão frente aos complexos desafios e exigências de produtividade e de inovação impostos às organizações.

Palavras-chave: Burocracia. Gestão organizacional. Tecnologia da informação.

\section{ABSTRACT}

Information systems have played an important role in the improvement of organizational processes, whether in private or in public institutions. However, the binomial bureaucracy/technology is still a challenge for many organizations. This article, based on a qualitative research and exploratory purpose, sought to find out, through a literature review, key features, malfunctions and relationship between the bureaucratic model weberiano and information systems in the current organizational context. It was noted that the advancement of information technology in the public and private sectors made possible not only the sophistication of their control mechanisms, but also improved their decision-making processes in relation to the complex challenges and productivity and innovation requirements imposed on organizations.

Keywords: Bureaucracy. Organizational management. Information technology.

1Professora da Universidade Federal Rural de Pernambuco (UFRPE) e da Faculdade Damas da Instrução Cristã (FADIC).

Doutora em Administração pela Universidade Federal de Pernambuco (UFPE).

2Professor da Unidade Acadêmica de Serra Talhada da Universidade Federal Rural de Pernambuco (UFRPE/UAST). Mestre

em Gestão do Desenvolvimento Local Sustentável pela Universidade de Pernambuco (UPE).

3Professora Susbstituta da Unidade Acadêmica de Serra Talhada da Universidade Federal Rural de Pernambuco (UFRPE/UAST).

Epecialista em Gestão Pública pela Universidade Federal Rural de Pernambuco (UFRPE). 


\section{INTRODUÇÃO}

Utilizando-se as lentes do senso comum seria difícil enxergar alguma relação entre sistemas de informação e burocracia. O uso de tecnologias da informação nos processos organizacionais representa um avanço em direção à maior produtividade, eficiência e visibilidade do negócio. Tecnologia representa progresso e burocracia, atraso. Isso mesmo, atraso!

Dependendo do tipo de organização a burocracia fica incrustada, posicionando-se como coisa estratégica, sendo tão importante quanto o plano de cargos e carreiras dos funcionários. Como exemplo, podese citar o departamento de custos de uma empresa privada ou o setor de protocolo de uma instituição pública, os quais funcionam como hospedeiros do vírus da burocracia.

O que as organizações vivenciam hoje e dizem que é decorrência da burocracia representa justamente as disfunções de um modelo cuidadosamente desenvolvido. São exageros que perduram por anos e que se originaram a partir de grandes mudanças no cenário organizacional. No âmbito privado, as empresas cresceram, o mercado globalizou-se, surgiram novos concorrentes, consolidaram-se a produção em massa e a diversificação. No horizonte estatal adveio o novo modelo de administração pública estratégica.

Muitas variáveis foram incorporadas às organizações e seus gestores temiam a perda do controle. Então, o excesso de papéis, a comunicação formalizada, as regras em demasia, dentre outros aspectos que se dizem burocráticos, foram incorporados às rotinas organizacionais para manter a harmonia administrativa.

Mas, o ambiente que se formava impunha outros desafios para as empresas privadas. Maior flexibilidade e rapidez de resposta às contingências do mercado impeliam-na a adotar um modelo burocrático mais flexível. Para tanto, a tecnologia foi sendo desenhada e redesenhada para dar suporte à criação de um novo perfil organizacional. A partir da automação e da informatização das tarefas e rotinas, antes manuais e artesanais, foram adquirindo maior velocidade, sem perderem o controle, pois os sistemas conseguiam, e conseguem cada vez mais, capturar os dados das transações e disponibilizá-los para uma gestão profissional, agora com maior visibilidade de seus processos e operações.

Na esfera pública, as preocupações em relação à funcionalidade do modelo burocrático e à aplicabilidade dos sistemas de informação relacionam-se diretamente ao desejo de mitigar as insatisfações dos usuários de serviços públicos, uma vez que a moderna Administração Pública ou gestão pública estratégica deve pautar-se na qualidade e na transparência (MATIAS-PEREIRA, 2010; KANAANE et al. 2010).

No entanto, a essência não mudou. A burocracia preza pelo controle, pela previsibilidade, pela eficiência e produtividade. Ferramentas são estabelecidas para garantir o resultado desejado, uma delas seria a tecnologia da informação, mas o que se percebe é a perpetuação de burocratismo, ou seja, empresas do setor privado e instituições públicas cujos processos ainda estão contaminados pelas disfunções burocráticas.

\section{PROCEDIMENTOS METODOLÓGICOS}

A pesquisa científica respalda-se pela utilização de métodos, normas e técnicas capazes de que assegurar a fidedignidade dos dados obtidos e, por conseguinte, validar os resultados obtidos. Para o caso deste estudo, foram adotados os procedimentos metodológicos classificados e expostos a seguir. 
Quanto aos fins o presente estudo possui uma finalidade exploratória, pois busca: o "aprimoramento de idéias ou a descoberta de intuições” a cerca da temática abordada (GIL, 2007, p.41-42). Quantos aos meios para a obtenção dos dados procedeu-se uma pesquisa bibliográfica fundamentalmente em livros, revistas e artigos científicos, selecionados com base em sua relevância e atualidade.

De acordo com Lakatos e Marconi (2003, p.158), essa pesquisa trata-se de um "apanhado geral sobre os principais trabalhos já realizados, revestidos de importância, por serem capazes de fornecer dados atuais e relevantes relacionados com o tema".

Durante todo esse processo de revisão literária realizou-se: um levantamento preliminar da literatura atual que aborda a temática escolhida, sua leitura, confecção de fichas, organização, interpretação e escrita do texto final GIL, (2007; 2008).

Sendo que a análise desses dados foi realizada através de uma abordagem predominantemente qualitativa, visto que, segundo Lima (2004) os teóricos e pesquisadores que adotam esse método, enfatizam que só é possível imprimir significado aos fenômenos humanos (e, consequentemente, sociais e organizacionais) por meio da interpretação e compreensão, em detrimento da mera quantificação.

\section{BUROCRACIA E BUROCRATISMO}

O termo burocracia apresenta diversos significados. Pode ser utilizado para designar um tipo de administração racional e eficiente, ou o seu contrário. Também pode ser utilizado para designar organização.

Segundo Alves (2004) a burocracia racional-legal apresenta um estatuto legal que dominantes e dominados acreditam possuir validade legítima sendo, portanto, motivador para a obediência desejada.

De modo mais amplo, pode-se dizer que a burocracia é uma estrutura social onde a direção das atividades coletivas é de responsabilidade de um aparelho impessoal hierarquicamente organizado, que deverá seguir critérios impessoais e racionais para a execução de suas ações (MOTTA, 2000).

De acordo com Silva (2008) a administração burocrática originou-se na primeira metade do século passado na Europa, como uma teoria que objetivava relacionar racionalidade técnica, eficiência e produtividade, pois, à medida que as organizações cresciam e a operacionalização de suas atividades tornavase mais complexa o modelo de organização racional consolidava-se.

Este trabalho objetiva averiguar, por meio de uma revisão de literatura, as principais características do modelo burocrático weberiano, suas disfunções e sua relação com os sistemas de informação no atual contexto das organizações públicas e privadas.

Max Weber, sociólogo alemão, foi o principal teórico que deixou em seus escritos uma bagagem conceitual, praticamente inquestionável, sobre a burocracia. Seus estudos buscaram sistematizar os fatos que estavam ocorrendo na sociedade moderna à luz de uma visita histórica a manifestações da lógica burocrática em diversos países. 


\section{REVISTA DE MESTRADOS PROFISSIONAIS}

Em suma, sua tese era de que a racionalidade moderna estava conduzindo a sociedade a uma sociedade burocrática (LODI, 2003), o que contribuiu para a construção da sociologia da burocracia cujos atributos principais seriam a alienação e o controle das pessoas ou dos trabalhadores. Para ele, a burocracia era um tipoideal, um modelo, de dominação racional-legal.

O Quadro 1 a seguir, traz uma síntese dos fatores que serviram de base para a estruturação do modelo burocrático.

Quadro 1 - Fatores que permitiram a consolidação da estrutura burocrática

I. Racionalização do direito - que passa a ser escrito e organizado com base em ordenamentos jurídicos em vez dos costumes e tradições não escritos;

II.Centralização do poder estatal - propiciada pela crescente facilidade de comunicação e transporte;

III. Surgimento e consolidação das indústrias nas cidades, da sociedade chamada sociedade em massa (expansão do sistema capitalista de produção).

Fonte: Adaptado de Peci e Sobral (2008, p.43-44)

A essência da burocracia é estabelecer regras gerais e regulamentações específicas para o pleno funcionamento da organização, indo desde a seleção de funcionários até a determinação de metas, objetivos, funções e deveres (MERCHIOR, 1990).

Verifica-se, dessa forma, a grande influência do modelo burocrático não apenas no setor privado, mas principalmente na administração estatal ou pública (SILVA, 2008).

Nas organizações industriais, Weber recomendava que houvesse uma estrutura hierárquica da autoridade e uma divisão de trabalho bem definida. Assim, estabeleceu um sistema que busca organizar, de forma estável e duradoura, a cooperação da grande massa de indivíduos que apresentam especializações diferenciadas de acordo com os tipos de tarefas existentes.

Para Nogueira (2007, p.76) "a formalidade, a impessoalidade, o profissionalismo e a hierarquia, aspectos basilares da organização burocrática, encontravam na divisão técnica do trabalho uma ferramenta poderosa para sua validação". Saliente-se que tais princípios sempre nortearam a gestão organizacional, especialmente a gestão pública.

O sistema proposto por Weber informa algumas tendências que definem a gestão e a organização burocráticas conforme resumido no Quadro 2 a seguir. 
Quadro 2 - Características e tendências da organização burocrática

I. Especialização funcional e especificação das tarefas. A descontinuidade das tarefas é suprimida e é estabelecido um fluxo de trabalho mais fluido.

II. Definição de uma hierarquia para exibir as funções e as posições do poder na organização.

III. "Contratualização" das relações organizacionais através de contratos de trabalho que explicitam deveres, direitos, obrigações e responsabilidades.

IV. Credenciamento dos funcionários mediante comprovação de suas qualificações.

V. "Carreirização" possibilitando ações de promoção do trabalhador.

VI. Processo de estratificação através da diferenciação por status.

VII. As normas devem ser seguidas independentemente das pessoas e servem para justificar e produzir ações legitimadas. A tendência aqui é para a formalização das normas.

VIII. Essa formalização requer que os gestores tomem por base documentos escritos, gerando uma base de informações que precisa de organização. A tendência gerada é a padronização desses documentos e também de procedimentos.

IX. A comunicação, a coordenação e o controle são centralizados.

X. As ações organizacionais são legitimadas a partir da diferenciação entre ações burocráticas e particulares.

XI. O poder pertence ao cargo e não ao funcionário que o ocupa, o que oficializa a ação organizacional.

XII. Há um distanciamento das pessoas em detrimento das ações oficiais da burocracia levando à impessoalidade das relações.

XIII. A "impessoalização" ocorre de acordo com sistemas disciplinares desenvolvidos na organização, o que leva à "disciplinarização" da ação organizacional.

Fonte: Adaptado de Clegg (1998)

Essas tendências da burocracia são mencionadas como variáveis e compõem o tipo-ideal de Weber. Como variáveis, são congeladas numa representação idealizada para servir de referência para o que pode ser encontrado numa organização com traços burocráticos (CLEGG, 1998).

Assim, pode-se localizar a organização num continuum de graus de burocratização: a organização poderia se aproximar mais ou se distanciar do modelo, pode também apresentar escassez ou excesso de burocratização.

A estrutura burocrática triunfou como modelo adequado às organizações por apresentar alguns benefícios determinantes para sua longevidade (Quadro 3). 


\section{Quadro 3 - Benefícios do modelo burocrático}

I. Há uma lógica científica, técnica, fundamentando os preceitos burocráticos;

II. Estabelecimento de análises racionais para o aprimoramento dos processos produtivos;

III. As relações de trabalho são profissionalizadas. Uma lógica é estabelecida para permitir a igualdade de todos perante as regras, o que reduz o favoritismo e clientelismos típicos de organizações tradicionais;

IV. As competências técnicas são formalizadas e registradas para que não haja perdas devido à tradição oral das comunidades artesanais e sociedades baseadas no costume e na tradição;

V. A estrutura burocrática impessoal, a formalização e a padronização permite que o modelo organizacional seja transposto a outras organizações num processo que pode ser chamado de isomorfismo.

VI. Há uma ética profissional estabelecida que regula as relações e comportamentos.

Fonte: Adaptado de Motta e Vasconcelos (2006)

Desse modo "a burocratização é o meio específico por excelência para transformar uma 'ação comunitária' (consensual) numa ação 'associativa' racionalmente ordenada (WEBER, 1999, p. 222)’.

Percebe-se que a teoria da burocracia é constituída de uma racionalidade, dita instrumental por Weber, que conduz a organização a ganhos em produtividade e eficiência através de uma administração profissional.

Por outro lado, o uso excessivo da burocratização (rigidez excessiva nas normas, inflexibilidade, centralização demasiada, controle que engessa, dentre outros fatores) conduz a disfunções, ou burocratis- mos (LAPASSADE, 1967) que fogem da proposta idealizada para esse modelo.

São consequências não previstas talvez por não serem considerados os grupos informais nas organizações e também as diferenças individuais entre as pessoas.

A burocracia é uma criação humana, mas o próprio homem falha ao colocá-la em funcionamento. Lapassade (1967) fala que o funcionamento burocrático é um "disfuncionamento". A racionalidade operacionalizada não segue os preceitos burocráticos, abandonando a lógica da eficiência prescrita pela "melhor maneira" (one best way).

O resultado é um aparelho engessado, alienante e inflexível, que se caracteriza pelo apego aos regulamentos, problemas de controle e supervisão, excesso de formalismo e papelório, resistência a mudanças, centralização da comunicação e das decisões e padronização excessiva (ver Quadro 4). 
Quadro 4 - Disfunções do modelo burocrático nas organizações

\begin{tabular}{|rl|}
\hline I. & Particularismo - Defesa de interesses de determinados grupos de poder; \\
II. & Satisfação de interesses pessoais - Nepotismo, corrupção; \\
III. & $\begin{array}{l}\text { Excesso de regras - Multiplicidade de exigências, papelório, excesso de } \\
\text { formalização. }\end{array}$ \\
IV. & $\begin{array}{l}\text { Hierarquia e individualismo - Engessamento do processo decisório, luta } \\
\text { pelo poder e vaidades exacerbadas. }\end{array}$ \\
V. & Mecanicismo - Cargos limitados, super-especialização, alienação.
\end{tabular}

Fonte: Adaptado de Maximiano (2006, p.105)

A normatização recomendada tem o propósito de guiar as ações organizacionais num sentido único para que objetivos sejam atingidos.

Quando seguir as normas passa a ser um fim em si mesmo, e não um meio, o grau de eficiência é baixo e os trabalhadores passam a seguir e a perpetuar um ritual que se distancia da prática desejada. Esse apego a regras e rotinas inflexibiliza o sistema tornando-oineficiente.

Para Gouldner (CROZIER, 1981), existia um círculo vicioso que se apoiava na existência de um problema de controle e supervisão.

A normatização, ou o estabelecimento de regras impessoais, reduzem as tensões que surgem pelo exercício do controle e da supervisão, mas, ao mesmo tempo, perpetuam o comportamento desmotivado dos trabalhadores gerando ações minimalistas limitadas às regrasimpostas.

É possível então que os membros da organização se aprisionem em um conjunto auto-reforçado de ações cada vez mais inadequado às exigências de novas questões ou problemas que podem acontecer (CLEGG, 1998).

O esforço então se concentra na manutenção da harmonia da máquina burocrática, evitando conflitos e reproduzindo padrões já estabelecidos. No entanto, as disfunções por ora apresentadas inabilitam a organização a atuar com graus de eficiência satisfatórios bem como de se ajustar a partir de feedbacks do ambiente externo. Novos padrões com base na racionalidade weberiana devem emergir para por fim à desordem provocada pelo burocratismo.Um novo ator entra em cena para contracenar com o modelo burocrático, a Tecnologia da informação (TI). Esse novo integrante oferece a possibilidade de análise do modelo de atuação em uso e também permite redesenhar as ações que destoam do modelo requerido. 


\section{SISTEMAS DE INFORMAÇÃO E SUA INTERFACE COM AS ORGANIZAÇÕES ATUAIS}

Os sistemas de informação são responsáveis por coletar, processar, armazenar, analisar e disseminar infor- mações para propósitos específicos (TURBAN, 2010).

Como qualquer sistema, seu fluxo (Figura 1) contém entradas, processamento e saída, podendo ser incluí- do um sistema de feedback e controle.

Figura 1 - Esquema dos sistemas de informação.

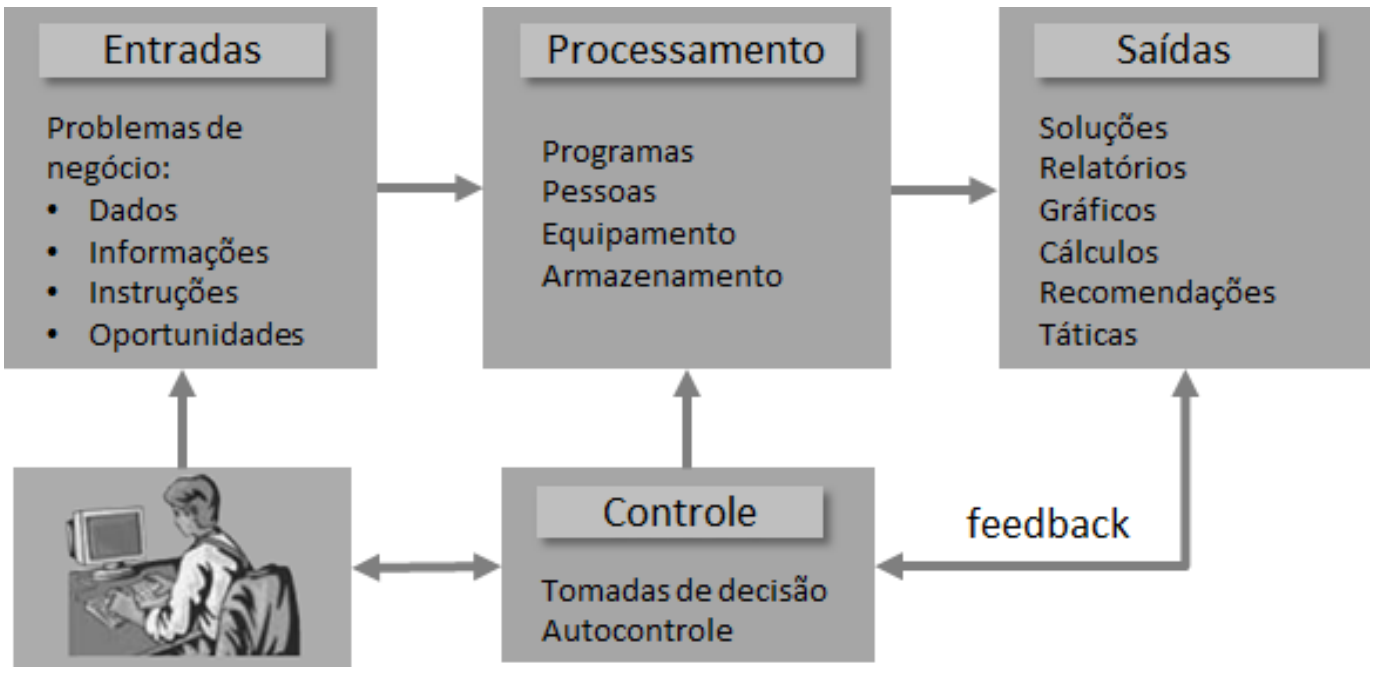

Fonte: Turban (2010, p. 34).

No processamento atuarão as pessoas e a tecnologia da informação (TI). Em uma definição mais ampla, tecnologia da informação refere-se ao aparato tecnológico dos sistemas de informação, como: software (programas); hardware (equipamentos); banco de dados (dispositivos de armazenagem) e redes (sistema de conexões, podendo ser sem fio). Pode-se considerar que a TI é um subsistema dos sistemas de informação.

Então as entradas são os recursos que são processados para que resultados (ou saídas) sejam produzidos. As saídas expressam o produto do sistema e alimentam um sistema de controle que verifica e compara o resultado com os objetivos desenhados para o sistema, neste caso, a organização.

A partir do controle, ajustes podem ser realizados em cada etapa do fluxo do sistema, permitindo uma adaptação dinâmica às necessidades para o qual foi desenhado ou a demandas emergentes.

A atuação dos sistemas de informação, apoiados por TI, nas organizações assumiu dimensões relevantes ao conferir melhores resultados operacionais e maior efetividade nas atividades gerenciais. O Quadro 5 exibe algumas de suas capacidades: 
Quadro 5 - Principais capacidades de sistemas de informação computadorizados

\section{Principais capacidades de sistemas de informação computadorizados}

- Automatizar processos através de especificação e padronização.

- Monitorar o desempenho dos processos através de parâmetros estabelecidos.

- Promover melhorias nos processos adotando boas práticas.

- Facilitar a execução das tarefas através de sistemas específicos.

- Integrar os processos intra e interorganizacionais.

- Armazenar dados e informações decorrentes das transações organizacionais.

- Permitir acesso rápido e barato a grandes quantidades de informações.

- Realizar cálculos numéricos em alta velocidade e em grande volume.

- Automatizar o processo decisório através de ferramentas analíticas sofisticadas.

- Elaborar previsões, simulações e cenários.

- Aumentar a visibilidade das operações organizacionais.

- Fornecer comunicação rápida, exata, confiável e barata dentro e entre organizações, a qualquer hora e em qualquer lugar.

- Controlar a execução das tarefas pelos funcionários.

- Acompanhar o desempenho da organização frente aos objetivos definidos.

Fonte: Baseado em Côrtes (2008); Turban et al (2010).

Os sistemas de informação atuam nos três níveis organizacionais: operacional, tático e estratégico.E são classificados, segundo Lussier, Reis e Ferreira (2010), em três tipos básicos: sistemas de processamento de transações - voltados para os assuntos e registros rotineiros e recorrentes; sistemas de informação gerencial muito utilizados para as decisões tomadas no dia a dia organizacional e sistemas de suporte à decisão - mais flexíveis e auxiliam nas decisões que envolvem problemas complexos.

No nível operacional, atuam na automação de processos permitindo que as transações, antes manuais, sejam realizadas com apoio computacional. Isso gera um diferencial relevante, pois esses sistemas também são responsáveis pela captura dos dados que brotam a cada operação realizada, como o registro de ponto de um funcionário, a movimentação de ativos no ambiente físico da organização, lançamentos contábeis, recebimento de mercadorias, dentre outros. Os processos apoiados são especificados e padronizados para que haja univocidade nas operações desempenhadas. Os dados capturados são armazenados, processados e disponibilizados como informações para apoiar as atividades de gestão. 
Os gestores precisam de informações consolidadas para visualizar, monitorar, controlar e coordenar diversos processos que ocorrem ao longo de toda a organização. Os sistemas de informação gerencial (SIG) são designados para apoiar os gestores de diferentes áreas na organização a fim de suprir as necessidades específicas de cada função. Através de tecnologias mais robustas, os SIGs habilitam supervisores, coordenadores e gerentes a desempenharem suas tarefas sem a necessidade da presença física no local no momento em que ocorre uma transação.

Já no nível estratégico, os sistemas de apoio ao executivo providenciam uma visibilidade ampla do desempenho de toda a organização, facilitando o processo decisório de questões mais complexas. Os executivos, assim como os gestores, contam com ferramentas estatísticas que desenham visões sobre aspectos da organização.

O cerne dos SI são os processos organizacionais. Desde que houve a possibilidade de utilizar sistemas apoiados por computador nas organizações, a racionalidade que guiou o desenvolvimento dos sistemas ancorou-se nas tarefas existentes e na forma pela qual os trabalhadores as realizavam. A preocupação inicial foi desenvolver uma linguagem única, estabelecendo métodos específicos e roteirizados para o desempenho de cada tarefa para então construir uma plataforma integrada, permitindo a comunicação entre os diversos sistemas funcionais.

A tecnologia da informação (TI) promoveu um impacto na natureza do trabalho e seu ambiente transformando o modelo de competitividade que passou a se fundamentar em informação e processos (ALTER, 2002). A ideia é promover uma estrutura flexível de negócio (VENKATRAMAN, 1994) a fim de permitir ajustes sistemáticos em função das demandas externas e internas, através de uma plataforma integrada de operações.

De fato, a tecnologia surge como uma poderosa forma de se obter um aumento na produtividade, impulsionando as organizações tanto no setor privado como no público a buscarem continuamente novas soluções. Os processos de obtenção e manipulação das informações são beneficiados pela rapidez de tratamento.

Todavia, para uso desse ferramental, vinculado à chamada tecnologia da informação, direcionam-se altos investimentos (O’BRIEN, 2002). Mas esses investimentos têm causado um certo desapontamento por parte de seus investidores devido à tendência de uso da tecnologia para mecanizar processos configurados sob moldes antigos.

Venkatraman (1994) diz que os benefícios da tecnologia de informação serão marginais se houver uma sobreposição desta às condições organizacionais pré-existentes, como: estratégias, estruturas, processos e cultura. Ele acredita que o poder da TI, em qualquer organização, reside na reestruturação dos relacionamentos nas redes de trabalho do negócio para alavancar um vasto arranjo de competências que propiciarão melhores produtos e serviços. 
Então, a tecnologia per si não conseguirá garantir o sucesso da organização (ALBUQUERQUE, 2004). Ela é sim um meio para isso, mas os processos organizacionais precisam ser revistos e adequados. As pessoas (funcionários) devem se envolver neste processo e assumir uma postura colaborativa, compartilhando informações e comprometendo-se com a reestruturação organizacional.

Diante deste contexto, percebe-se uma evolução nos modelos de gestão, o que também se relaciona aos sistemas de informação, no sentido de acompanhar a complexidade das organizações, pois é crescente a quantidade de variáveis que são incorporadas como instrumentos para o desempenho das atividades nos diferentes níveis organizacionais. De acordo com Tapscott e Caston (1995) a organização de antigamente já não funciona mais, a flexibilidade, o trabalho em equipe, a produtividade e o compromisso (no lugar do controle) devem fazer parte dessa nova configuração, visto que, de acordo com Daff (2008) dentre os desafios para as organizações atuais constam as capacidades de: responder com rapidez às mudanças e às demandas, não só dos seus clientes, mas te todo o seu público estratégico (stakeholders) e operar em um ambiente cada vez mais digital. E esse entendimento é válido tanto para o setor público quanto para o privado.

\section{UM OLHAR “BUROCRÁTICO” SOBRE OS SISTEMAS DE INFORMAÇÃO}

Anova organização precisa assumir uma postura flexível para se adaptar às contingências do ambiente de mercado: intensa concorrência; ciclo de vida mais curto dos produtos; mercado global; necessidade de redução ou adequação de custos e intenso desenvolvimento tecnológico. A era é chamada de era digital ou era da informação, pois as bases para qualquer decisão estão fortemente amparadas por informação já que existem sistemas capazes de provê-la.

Segundo Motta (1993) a realidade organizacional precisa ser recriada, envolvendo os indivíduos que dela fazem parte e buscando meios de influenciar suas ações.

Então, onde andará a organização burocrática? Aquela que se baseia no modelo racional-legal que promete previsibilidade e controle, que divide as tarefas e que trabalha com uma hierarquia bem definida. Agora que a organização conta com tecnologia da informação e com os sistemas de informação, alguns pensam em desburocratizá-la. Parece que não é bem assim que os fatos estão acontecendo. Paula (2002) denomina esse fenômeno de falácia da desburocratização já que considera a adaptação da burocracia ao novo contexto histórico.

Uma nova organização surge no lugar da burocrática (hierarquia rígida, centralização, forte regulamentação, baseada na disciplina e divisão do trabalho). Aorganização pós-moderna (CJEGG e HARDY, 1996) que se caracteriza pela descentralização, por uma estrutura conectada em redes de comunicação baseada em TI e por uma liderança libertadora que resolve conflitos e problemas com base no compromisso, abertura, confiança e relacionamento (PAULA, 2002).

A busca por retornos em curto prazo para os acionistas além de um pronto atendimento a demanda do consumidor, as novas organizações precisam flexibilizar a produção, manter uma estrutura de inovação sistemática, facilitar o trabalho em equipe, agilizar a execução dos processos. Essa nova configuração permite que os funcionários tenham mais controle sobre suas atividades, ou seria um pseudo-controle? 
As novas tecnologias da informação permitem monitoramento e controle das atividades dos funcionários através de uma sofisticada vigilância pela tela do computador (REED, 1996), perpetuando-se as formas de disciplina e controle nas organizações.

Aracionalidade por trás dos sistemas de informação é burocrática, só que numa outra roupagem. Esses sistemas prometem: visibilidade, controle, produtividade, previsibilidade, redução de erros, comunicação eficaz e apoio à tomada de decisão. Além disso, trabalham com forte apelo funcional, onde atuam exatamente nas demandas de cada função da organização.

A organização, agora informatizada, carrega a lógica burocrática materializada nas variáveis que se repetem, mas de uma forma diferente (Figura 2).

Figura 2 - Sistemas de informação e as variáveis da burocracia

Fonte: Elaborado pelos autores

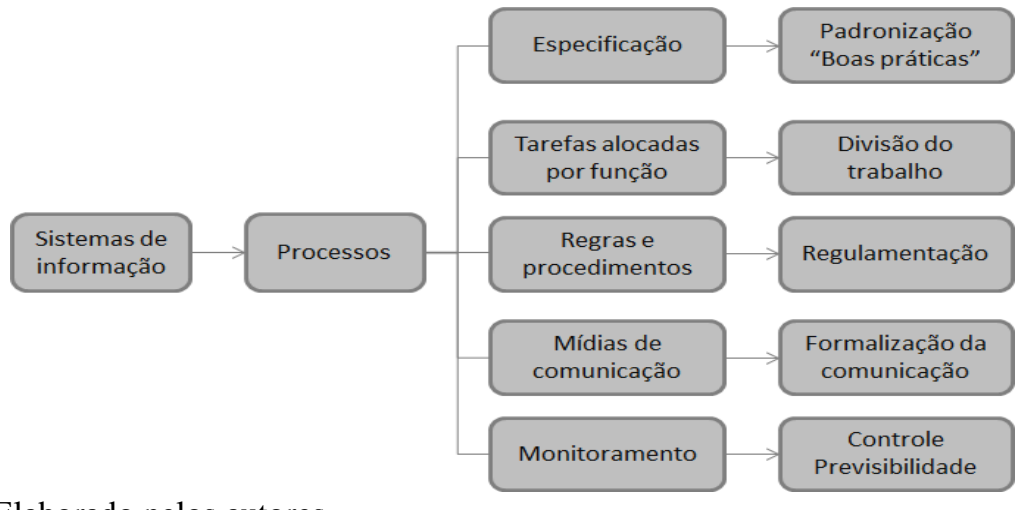

De acordo com o desenho exibido na Figura 2, os processos figuram papel principal na lógica que norteia os sistemas de informação. A partir deles, algumas características da burocracia podem ser identificadas:

- Padronização: os processos são especificados, estudados e, se necessário, melhorados a partir de “boas práticas”. Essa prática permite que, mesmo com a rotatividade de funcionários, não se perca a forma de execução as tarefas, que são registradas e armazenadas numa base de dados centralizada;

- Divisão do trabalho: os funcionários são alocados em funções específicas e suas tarefas são estabelecidas. Com a prática de gestão de processos que conta com sistemas de automação de processos, é possível alocar todo o processo numa trilha automatizada, onde os responsáveis por cada etapa são acionados via sistema para que executem suas tarefas;

- Regulamentação: há definição e regras e procedimentos, mas esses não apresentam de forma preponderante o atributo da rigidez. Busca-se manter o registro dinâmico dessas regras a fim de garantir o bom funcionamento da organização, mas muitas dessas regras são introspectadas pelos funcionários sem, necessariamente, precisar de registros formais.

- Formalização da comunicação: o advento das mídias de comunicação, como o e-mail, é possível ter registros das comunicações sem a necessidade de armazenar o documento fisicamente. As mensagens que são trocadas por correio eletrônico corporativo são passíveis de monitoramento e registro. As comunicações informais também são formalizadas por meio de mensagens eletrônicas. 
- Previsibilidade: os sistemas de informação estão cada vez mais robustos e sofisticados e contam com a estatística para gerar informações referentes a tendências e previsões. Assim, a composição de possíveis cenários bem como a previsão de eventos pode acontecer com maior grau de acerto.

- Controle: é uma variável amplamente beneficiada pela tecnologia da informação. As ferramentas de monitoramento permitem visualizar praticamente toda a atuação do funcionário durante a sua jornada de trabalho.

Um problema que emerge com a automação dos processos é a ausência de uma análise prévia. E, se- gundo Venkatraman (1994), quando se automatizam processos ineficientes têm-se como resultado processos ineficientes automatizados. É nesse ponto que o burocratismo se perpetua, pois os excessos da burocracia (suas disfunções) não são sanados acometendo a organização de um câncer silencioso, mas voraz, que conduz o processo à ineficiência e conduz a organização ao insucesso.

\section{CONCLUSÕES}

O exercício de pensar os sistemas de informação à luz da burocracia descortina aspectos que são pouco explorados por estudiosos que analisam o modelo burocrático apenas pelo ângulo das suas disfunções.

Além de ser um sistema com lastro em uma racionalidade-legal que propõe um tipo-ideal de organização para servir de representação e guia, a burocracia é um sistema de dominação por excelência.

O novo paradigma focado na era informacional traz novas perspectivas para a organização, principalmente pela inserção da Tecnologia da informação e de Sistemas de informação cada vez mais robustos e onipresentes. Manter a sociedade organizacional alinhada aos objetivos e motivada a trilhar os caminhos desejados é um desafio que transcende aTI.

Outro desafio é a necessidade de uma sistemática de inovação. Na burocracia tradicional, não havia essa prerrogativa. $\mathrm{O}$ ambiente estável e previsível não demandava esse movimento de lançar produtos novos no mercado em intervalos curtos de tempo. Hoje a obsolescência do produto é planejada e cada vez mais os ciclos de vida são menores. Cabe inserir mais uma regra: inovar. Seria mesmo uma regra? Weber prevê que as regras são introjetadas pelos indivíduos e transformadas em comportamentos. Na empresa contemporânea, inovar é um comportamento esperado dos funcionários. E na organização pública tal intuito também se faz presente.

O advento da tecnologia da informação traz uma nova roupagem aos elementos burocráticos (saudáveis), mas também traz desafios às organizações que precisam de uma postura flexível para se adaptar às contingências que se tornarão visíveis por meio dos produtos de informação disponíveis. Burocratismos ainda existirão e a própria tecnologia ajudará na manutenção dos mesmos. Cabe aqui um novo tipo de profissional, disposto a desfrutar das informações disponibilizadas e a despertar uma postura analítica e crítica a fim de recriar o sistema-organização diante das demandas que surgem.

Este estudo proporcionou um novo olhar sob os sistemas de informação, fugindo do viés apropriado pelos estudos realizados anteriormente nessa área. Perceber a racionalidade por trás dos sistemas engrandeceu a bagagem conceitual até então adquirida e permitiu uma análise mais expansiva do tema. 
Portanto, constatou-se que o binômio burocracia/tecnologia, uma vez sendo procedidas as necessárias adequações, pode trazer grandes benefícios tanto para instituições públicas quanto para empresas privadas; e que os sistemas de informação são importantes ferramentas de controle e de auxílio ao processo decisório nas organizações contemporâneas.

\section{REFERÊNCIAS}

ALBUQUERQUE, C. R. S. Por uma maior interação com o cliente: um estudo baseado no conceito de gestão do relacionamento com o cliente (CRM). 2004. Dissertação (Mestrado em Administração) - Universidade Federal de Pernambuco (UFPE), Recife.

ALTER, S. Information Systems: a management perspective. 4rd. Ed. Addison Wesley: Boston, 2002.

ALVES, S. Racionalidade, carisma e tradição nas organizações empresariais contemporâneas. Recife: Editora Universitária UFPE, 2004.

CLEGG, S. R., HARDY, C. Organizations, Organization and Organizing. In: CLEGG, S. R.,HARDY,C. \& NORD, W.R.Handbook of Organization Studies. London: Sage Publications, 1996, p.1-28.

CLEGG, S. R. As organizações modernas. Celta editora: Oeiras, 1998.

CÔRTES, P.L. Administração de sistemas de informação. São Paulo: Editora Saraiva, 2008.

CROZIER, M. O fenômeno burocrático. Brasília: Ed. UNB, 1981.

DAFT, R. L. Organizações: teorias e projetos. 2. ed. Tradução: Andréa Castellano Mostaço, Cláudia Mello Belhassofe Harue Ohara Avritchar. São Paulo: Cengage Learning, 2010.

GIL, A. C. Como elaborar projetos de pesquisa. 4.ed. São Paulo: Atlas, 2007.

Métodos e técnicas de pesquisa social. 6. ed. São Paulo: Atlas, 2008.

KANNANE, R.etal.Gestãoestratégica ea visãodofuturo.In:KANNANE,R.;FIEL,FILHO,A.;FERREIRA,M.G.Gestãopública: planejamento, processo, sistemas de informação e pessoas. São Paulo: Atlas, 2010. Cap. 3, p.34-70.

LAKATOS, E. M.; MARCONI, M. A. Fundamentos de metodologia científica. 5. ed. São Paulo: Atlas, 2003.

LAPASSADE, G. Burocracia, burocratismo, burocratização em MORIn, E. A burocracia. Lisboa: Ed. Sociocultur, 1967.

LODI, J. B. História da administração. São Paulo: Pioneira Thomson Learning, 2003.

LUSSIER, R.N.;REIS, A.C.F.;FERREIRA, A. A. Fundamentos de Administração. Traduçãode Guilherme Rocha Basílioe Marta Reyes Gil Passos. São Paulo: Cengage Learning, 2010.

MATIAS-PEREIRA, J. Curso de Administração Pública. 3. ed. São Paulo: Atlas, 2010.

MAXIMIANO, A. C. A. Teoria geral da Administração: da revolução urbana à revolução digital. 6. ed. São Paulo: Atlas, 2006.

MERQUIOR, J. G. De Rousseau a Weber. Rio de Janeiro: Ed. Guanabara Koogan, 1990.

MOTTA, F.C. P.Controle social nas organizações. Revista de Administração de Empresas, v.33, n.5, p.68-87, set./out. 1993. (Originalmente publicado em 1979, revisitado por Isabella Gouveia de Vasconcelos e Thomaz Wood Jr.)

O que é burocracia. São Paulo: Brasiliense, 2000.

MOTTA, F.C. P.; VASCONCELOS, I. G. Teoria geral da administração. São Paulo: Thompson Learning, 2006. 


\section{REVISTA DE MESTRADOS PROFISSIONAIS}

NOGUEIRA, A. M. Teoria Geral da Administração para o século XXI. São Paulo: Ática, 2007.

PAULA, A. P.P. Tragtenberg revisitado: as inexoráveis harmonias administrativas e a burocracia flexível. Revista de Administração Pública, v. 36, n. 1, p. 127-144,jan./fev. 2002.

O’BRIEN, J. A. Sistemas de informação e as decisões gerenciais na era da internet. São Paulo: Saraiva, 2002.

PECI, A.; SOBRAL, F.Administração: teoria e prática no contexto brasileiro. PearsonPrentice Hall, 2008.

REED, M. Organizational theorizing: a historically contested terrain. In:CLEGG, S.R.,HARDY,C.\& NORD, W.R. Handbook of Organization Studies. London: Sage Publications, 1996.

SILVA, R. O. Teorias da Administração. São Paulo: Pearson Prentice Hall, 2008.

TAPSCOTT,D.;CASTON, A. Mudança de paradigma. São Paulo: Makron Books, 1995.

TURBAN, E.; LEIDNER, D.; McLEAN, E.; WETHERBE, J. Tecnologia da informação para a gestão. 6. ed. Porto Alegre: Bookman, 2010.

VENKATRAMAN, N. IT - Enable business transformation: from automation to business scope redefinition. Sloan Management Review, winter, 1994, p. 73-87.

WEBER, M. Economia e sociedade. v. 2. Brasília: Ed. UNB, 1999. 